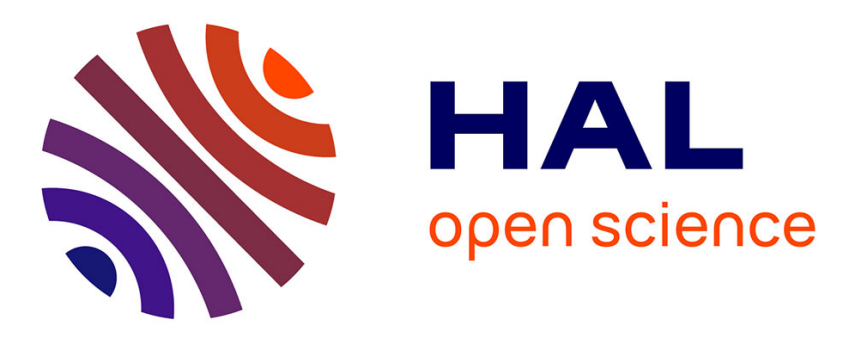

\title{
Direct electron-beam lithography on opal films for deterministic defect fabrication in three-dimensional photonic crystals
}

Patrick Ferrand, J. Seekamp, M. Egen, R. Zentel, S. G. Romanov, C. M. Sotomayor Torres

\section{To cite this version:}

Patrick Ferrand, J. Seekamp, M. Egen, R. Zentel, S. G. Romanov, et al.. Direct electron-beam lithography on opal films for deterministic defect fabrication in three-dimensional photonic crystals. Microelectronic Engineering, 2004, 73-74, pp.362-366. 10.1016/j.mee.2004.02.068 . hal-00272371

\section{HAL Id: hal-00272371 https://hal.science/hal-00272371}

Submitted on 29 Sep 2015

HAL is a multi-disciplinary open access archive for the deposit and dissemination of scientific research documents, whether they are published or not. The documents may come from teaching and research institutions in France or abroad, or from public or private research centers.
L'archive ouverte pluridisciplinaire HAL, est destinée au dépôt et à la diffusion de documents scientifiques de niveau recherche, publiés ou non, émanant des établissements d'enseignement et de recherche français ou étrangers, des laboratoires publics ou privés. 


\title{
Direct electron-beam lithography on opal films for deterministic defect fabrication in three-dimensional photonic crystals
}

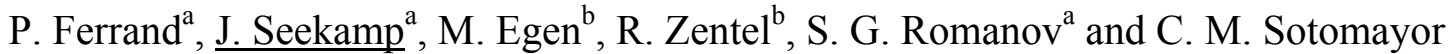
Torres $^{\mathrm{a}}$

${ }^{a}$ Institute of Materials Science and Department of Electrical and Information Engineering, University of Wuppertal, Gauss-Str. 20, D-42097 Wuppertal, Germany

${ }^{\mathrm{b}}$ Institute for Organic Chemistry, Department of Chemistry and Pharmacy University of Mainz Duesbergweg 10-14, D-55099 Mainz, Germany

E-mail: seekamp@uni-wuppertal.de

Keywords: photonic crystals, self-assembly, opal, electron-beam lithography, polymer

\begin{abstract}
The deterministic fabrication of microscopic structures in self-assembled threedimensional photonic crystals is reported. Microscopic 1- $\mu \mathrm{m}$ deep controlled structures as small as $5-\mu \mathrm{m}$ wide cavities and $2-\mu \mathrm{m}$ wide trenches have been fabricated using direct electron-beam writing on a PMMA opal film. The technique is highly accurate, versatile and is probably suitable to fabricate buried defects.
\end{abstract}


Photonic crystals ( $\mathrm{PhCs}$ ) are periodic index materials which allow the manipulation of photons in analogy to semiconductors with electrons [1]. Due to their potential to control light emission, routing and filtering, they constitute a promising approach towards a future generation of optoelectronic devices, combining high integration and high speed processing. In this context, research on self-assembled PhCs, e.g., opals, gained much attention [2], since this approach allows the realisation of genuine three-dimensional (3D) PhCs. This is probably the only approach able to provide a full control of light emission and propagation, with the submicron feature sizes required by optical wavelengths. Compared to competing techniques involving micromanipulation [3] or layer-by-layer growth [4], self-assembly is significantly more cost-effective and compatible with very large scale integration technologies.

With the crystal growth established, the next step is now to tailor its electromagnetic properties by acting at the structural level. Optical functions such as light channelling, filtering, can be obtained by breaking the regularity of the crystal, by modifying a few crystal cells. Already studied in the case of planar 2D PhCs, these basic functions could be significantly improved thanks to the better light confinement provided by a 3D PhC [5]. A structuring method using multiple-photon polymerization has been recently demonstrated [6], but the volume of the smallest structure is limited by optical diffraction to $\lambda^{3}$, where $\lambda$ is the laser wavelength [7]

In this paper, we demonstrate a technique which allows to fabricate microscopic intentional defects in opal films using electron beam lithography (EBL). Our approach consists in using an opal film as an EBL resist. The fabrication process of a threedimensional photonic crystal film with intentional defects is schematically represented in 
Fig. 1. After the crystal is grown on the substrate in a vertical position [8], the structuring is a two-step process. First, the opal film is locally exposed to an electron beam, followed by a development in a solvent to remove selectively the exposed material.

\section{Experimental}

Colloidal monodisperse poly(methyl methacrylate) (PMMA) microspheres were synthesized using the routine described elsewhere [9]. The polymer colloids had the measured molecular weight of $200000 \mathrm{~g} / \mathrm{mol}$ with a measured polydispersity index of 2.4. The (100) silicon substrates were cleaned by a standard process, hydrophilized in a $\mathrm{H}_{2} \mathrm{O}_{2}(35 \%): \mathrm{NH}_{3}(25 \%): \mathrm{H}_{2} \mathrm{O}(1: 1: 5)$ bath for 3 hours and rinsed in deionised water. The sedimentation was performed by drawing up the substrate in a vertical position [8] at a velocity of about $300 \mathrm{~nm} / \mathrm{s}$ from a $3 \mathrm{wt} \%$ suspension of spheres of diameter $325 \mathrm{~nm}$ or $400 \mathrm{~nm}$. With these parameters, the opal films were about $10 \mu \mathrm{m}$ thick. All these processes were carried out at ambient conditions. The film was sintered at $80^{\circ} \mathrm{C}$ for two hours in air. EBL was carried out using a Philips XL30-SFEG SEM equipped with a Raith Elphy Plus EBL control unit at a $V_{\text {acc }}$ between 2 and $30 \mathrm{kV}$ and a free working distance of $5 \mathrm{~mm}$. Typical exposure dose was $400 \mu \mathrm{C} / \mathrm{cm}^{2}$. Fine-tuning of the beam focusing, writing location and orientation was possible by a preliminary $5 \mathrm{~s}$ scan of the whole writing field for imaging, with a dose lower than $100 \mathrm{nC} / \mathrm{cm}^{2}$, insufficient to expose the material. After exposure, the samples were developed for $20 \mathrm{~s}$ in a solution of methyl isobutyl ketone (MIBK) and then placed in a solution of isopropanol to stop the development process for $20 \mathrm{~s}$. The samples were dried in a flow of dry nitrogen. Prior to 
imaging with a Philips XL30-TMP SEM, the samples were sputtered with a thin film of gold.

\section{Results}

In our approach, the thickness of our resist film is significantly larger than the few hundreds nanometres that are commonly used in EBL [10]. In these conditions, the film thickness and the penetration depth of the incident electrons are comparable. Moreover, this later can be driven by the acceleration voltage $V_{\text {acc}}$, which give the opportunity to master the writing depth.

Thus, compare to other exposure parameters (magnification, spot size, step size, etc.), which affect the in-plane resolution and writing time, $V_{\text {acc }}$ is the most relevant one for three-dimensional structuring purposes. Several values were tested and are summarized in Table 1. In order to have a working definition of lateral resolution in opal films, we have considered here the sharpness of the corners compared with the sphere diameters, expressed in radius of curvature. High $V_{\text {acc }}$ provide a good in-plane resolution, as illustrated in Fig. 2. However, optical microscopy observations (not presented here) show that the bottom of the film is melted by the process. On the contrary, low $V_{\text {acc }}$ result in a very shallow depth of writing, but a worse lateral resolution. With our material, the best working conditions, which are the trade-off between writing depth and resolution, were found to be the $2-10 \mathrm{kV}$ range, giving rise to a range of controllable writing depths from $0.5 \mu \mathrm{m}$ up to $1.8 \mu \mathrm{m}$. In Fig. 3, we present SEM micrographs of various structures fabricated with a $V_{\text {acc }}=5 \mathrm{kV}$, which resulted in a writing depth of about $1 \mu \mathrm{m}$, i.e., 3-4 layers of spheres. 
The accuracy of the process can be evaluated in Fig. 3a and its magnified image. The orientation of the cavity matches the orientation of the $\mathrm{PhC}$ lattice. The sharpness of the edges as well as the small radius of curvature at the corners demonstrates that the lateral resolution is of the order of magnitude of one sphere diameter or better. The bottom surface of the cavity is clearly flat on the scale of the sphere diameter, but it is covered by small particles. These are probably residues of incompletely dissolved spheres, indicating that the exposure parameters and the developing conditions need a better tuning. Nevertheless, in the present case, the remarkable size uniformity of these particles constitutes unambiguous evidence that the bottom surface of the cavity follows the $\mathrm{PhC}$ lattice. This high accuracy allows the writing of smaller cavities, like the one illustrated in Fig. 3b, although it is more difficult to distinguish the bottom surface due to shadowing. Beyond such structures the process is also suitable for large-scale structuring, such as the array of parallel trenches shown in Fig. 3c. The later features were written on an area of $100 \times 100 \mu \mathrm{m}^{2}$, over which the structuring was homogeneous. Furthermore, there is no doubt that this structuring process has clear up-scaling potentials towards patterning several $\mathrm{cm}^{2}$.

We have shown that EBL affects preferably the upper layer of the opal film, however this technique could be extended towards the fabrication of buried defect structures, by taking advantage of two specific properties of opal films, namely, the possibility of growth interrupt [11] and the open porosity of the film. For example, buried defects could be fabricated by the following three-step process: i) definition of defect structures by EBL, ii) subsequent growth of another film on the first one and iii) development of the exposed and buried spheres, within reach of the developing solvent thanks to the porous nature of 
the material. If, in addition, a controlled infilling of the voids with a high index material to achieve a complete photonic bandgap [12] were carried out, this approach would offer a unique way to create genuine 3D highly confined optical microstructures.

In summary, a controlled way to break the periodicity of 3D PhCs using EBL on PMMA opal films has been reported. Microscopic defects such as hexagonal cavities and straight trenches of controlled shape, depth and orientation have been fabricated. The technique is deterministic, accurate to within fraction of the opal spheres, versatile and potentially suitable to create buried defects.

\section{Acknowledgements}

The authors acknowledge the support of the German Research Council (DFG) Priority Program SPP 1113 "Photonic Crystals" and of the EU-IST Project PHOBOS Grant No. 19009. 


\section{References}

[1] J. D. Joannopoulos, R. D. Meade, and J. N. Winn, Photonic Crystals: molding the flow of light. (Princeton University Press, Princeton, 1995); J. D. Joannopoulos, P. R. Villeneuve, and S. Fan, Nature 387 (1997), 830.

[2] V. N. Astratov, V. M. Bogomolov, A. A. Kaplyanskii, A. V. Prokofiev, L. A.

Samoilovich, S. M. Samoilovich, and Y. A. Vlasov, Nuovo Cimento 17D (1995), 1349.

[3] F. Garcia Santamaria, H. T. Miyazaki, A. Urquia, M. Ibisate, M. Belmonte, N.

Shinya, F. Meseguer, and C. Lopez, Adv. Mater. 14 (2002), 1144.

[4] S. Noda, K. Tomoda, N. Yamamoto, and A. Chutinan, Science 289 (2000), 604.

[5] M. Bayindir, E. Ozbay, B. Temelkuran, M. M. Sigalas, C. M. Soukoulis, R. Biswas, and K. M. Ho, Phys. Rev. B 63 (2001), 081107; A. Chutinan, S. John, and O. Toader, Phys. Rev. Lett. 90 (2003), 123901.

[6] W. M. Lee, S. A. Pruzinsky, and P. V. Braun, Adv. Mater. 14 (2002), 271.

[7] B. H. Cumpston, S. P. Ananthavel, S. Barlow, D. L. Dyer, J. E. Ehrlich, L. L. Erskine, A. A. Heikal, S. M. Kuebler, I. Y. S. Lee, D. McCord-Maughon, Qin Jinqui, H. Rockel, M. Rumi, Wu Xiang Li, S. R. Marder, and J. W. Perry, Nature 398 (1999), 51.

[8] Z. Z. Gu, A. Fujishima, and O. Sato, Chem. Mater. 14 (2002), 760.

[9] M. Müller, R. Zentel, T. Maka, S. G. Romanov, and C. M. S. Torres, Chem. Mater. 12 (2000), 2508.

[10] M. A McCord and M. J. Rooks, in Handbook of microlithography, micromachining, and microfabrication, edited by P. Rai-Choudhury (SPIE Optical Engineering Press, Bellingham, Washington, 1997), Vol. 1, pp. 139. 
[11] P. Jiang, G. N. Ostojic, R. Narat, D. M. Mittleman, and V. L. Colvin, Adv. Mater. 13 (2001), 389.

[12] J. E. G. J. Wijnhoven and W. L. Vos, Science 281 (1998), 802. 


\section{Figure captions}

Fig. 1. Schematic representation of the EBL structuring process.

Fig. 2. SEM micrographs of structures fabricated using $V_{\text {acc }}=30 \mathrm{kV}$. Left panel: deep square structure. Right panel: Thin line showing the sharpness of the writing.

Fig. 3. SEM micrographs of structures fabricated in opal films. In all cases, the structure depth is about $1 \mu \mathrm{m}$. Micrographs on the right are close-ups. a) Array of 5- $\mu \mathrm{m}$ side hexagonal cavities. b) Array of 2- $\mu$ m side hexagonal cavities. c) Array of 2- $\mu \mathrm{m}$ wide straight parallel trenches. 


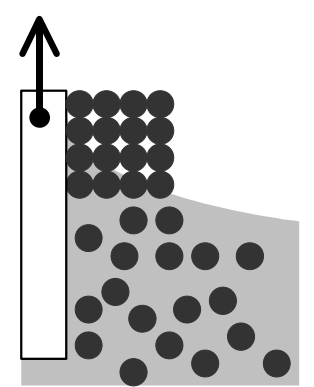

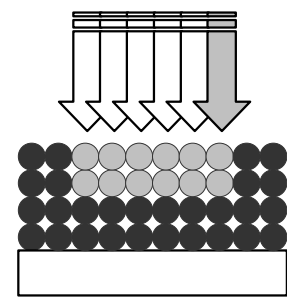

c) exposure

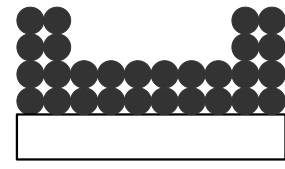

d) after developing b) sintering

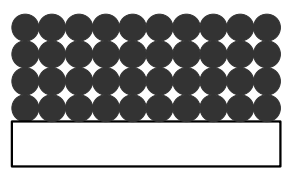

Fig. 1 

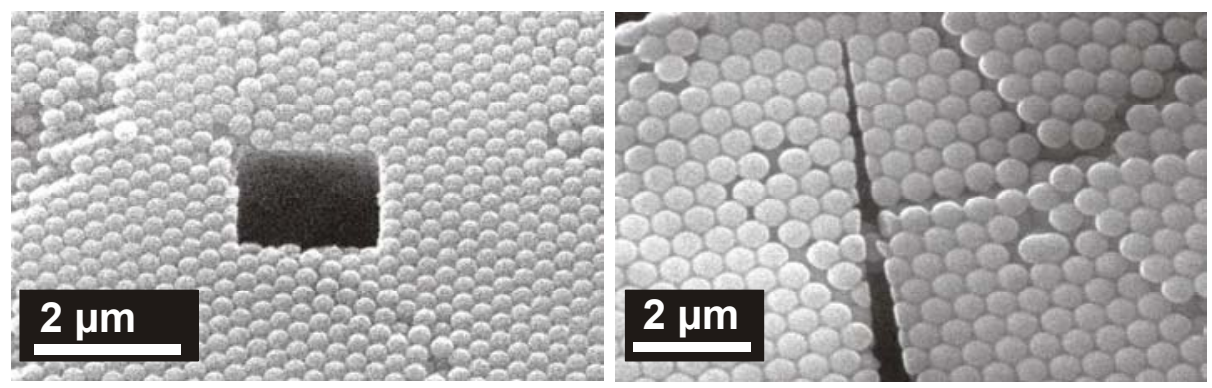

Fig. 2

P. Ferrand, Direct electron-beam lithography on opal films... 
a)
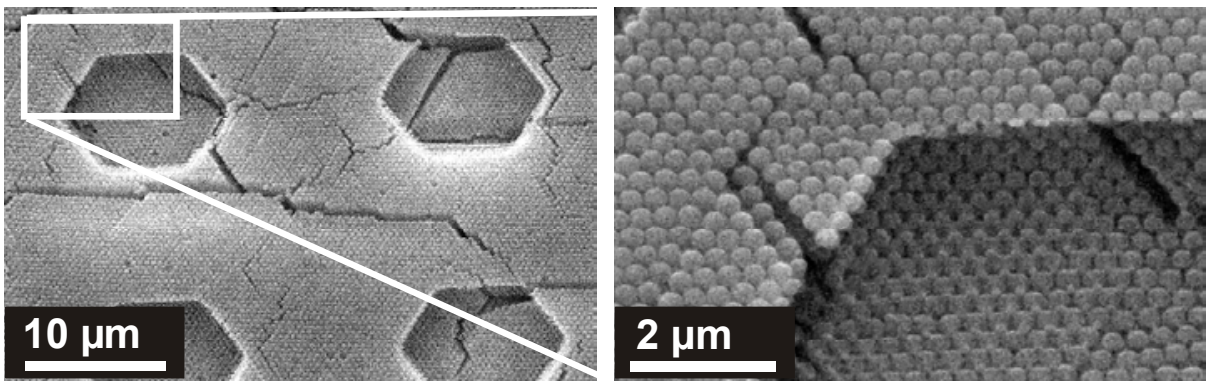

b)
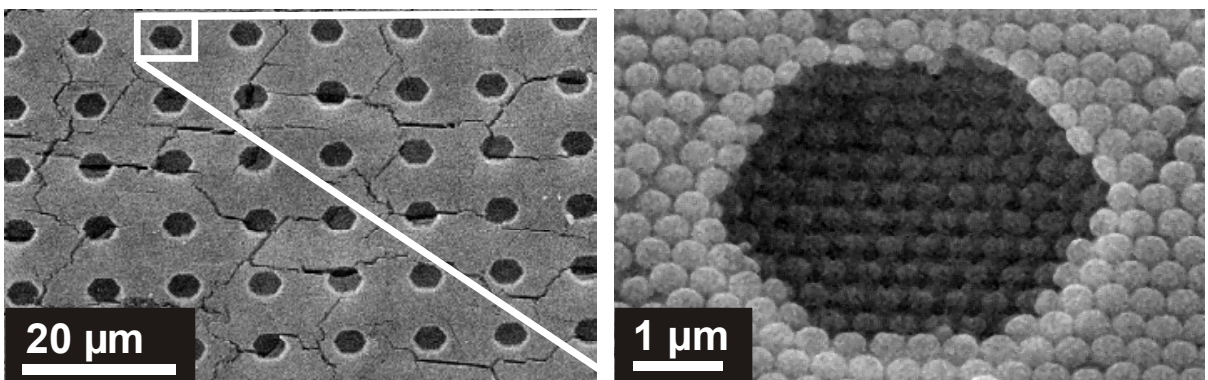

c)
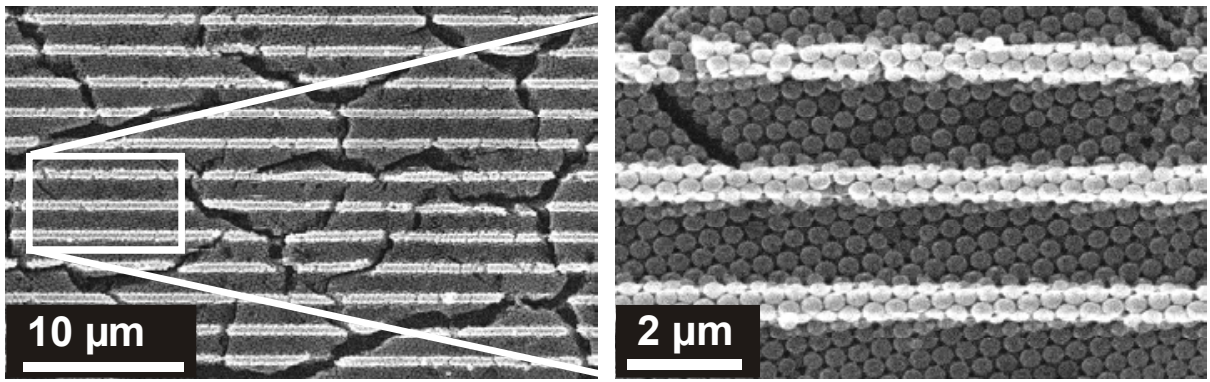

Fig. 3 


\section{Table caption}

Table 1. Summary of values of accelerating voltage and corresponding writing depth and lateral resolution. 
Table 1

\begin{tabular}{ccc}
\hline $\begin{array}{c}V_{\text {acc }} \\
(\mathrm{kV})\end{array}$ & $\begin{array}{c}\text { Writing depth } \\
(\mu \mathrm{m})\end{array}$ & $\begin{array}{c}\text { In-plane radius of curvature } \\
(\mu \mathrm{m})\end{array}$ \\
\hline 2 & 0.4 & 0.7 \\
5 & 1.0 & 0.5 \\
10 & 1.8 & 0.2 \\
30 & damage & $<0.1$ \\
\hline
\end{tabular}

